\title{
O CAPITAL FINANCEIRO NA OPERAÇÃO URBANA CONSORCIADA DA REGIÃO DO PORTO DO RIO DE JANEIRO
}

\author{
Financial capital on the urban operation Porto do Rio de Janeiro \\ Marcela Virginio Dametto * \\ *Discente do PPG em Geografia Humana - USP - damettomarcela@gmail.com
}

Recebido em 07/05/2018. Aceito para publicação em 25/06/2018.

Versão online publicada em 10/08/2018 (http://seer.ufrgs.br/paraonde)

\begin{abstract}
Resumo: 0 capitalismo contemporâneo apresenta um tipo de mercadoria denominada finança (CHESNAIS, $2005)^{1}$, que tem sua origem na intensificação da circulação de capital fictício e no aperfeiçoamento do sistema de crédito. As finanças ou "capital financeiro" vêm adquirindo uma movimentação autônoma e fluida, principalmente, a partir dos anos 2000, o que possibilitou sua inversão na produção do espaço urbano. Esta inversão se realiza por meio de estratégias estatais que reestruturam os espaços das cidades a fim de adaptálas às exigências atuais do modo de produção capitalista. Sendo assim, este artigo busca analisar a dinâmica da inversão de capital financeiro na produção do espaço da Operação Urbana Consorciada da Região do Porto do Rio de Janeiro, concretizada por meio da comercialização de Certificados de Potencial Adicional de Construção, os quais se comportam como ativos financeiros.
\end{abstract}

Palavras-chave: Capital financeiro; CEPACS; OUCRPRJ.

\begin{abstract}
The contemporary capitalism presents a kind of commodity named as finance (CHESNAIS, 2005), which has its origin in the intensified circulation of fictitious capital and in credit system improvement. The finances or "financial capital" has been acquiring autonomous and fluid movement, especially, since the year 2000 , and so, made its inversion into urban spatial production possible. That inversion is made through state strategies that restructures city's spaces in order to adapt them to capitalist system currently requirements. In that sense, this article aims to analyze the financial capital inversion dynamics on Operação Urbana Consorciada da Região do Porto do Rio de Janeiro spatial production, materialized through the commercialization of Certificados de Potencial Adicional de Construção which behaves as a financial asset.
\end{abstract}

Key-words: Financial capital; CEPACS; OUCRPRJ.

\section{Introdução}

Na medida em que a sociedade ${ }^{2}$ se reproduz historicamente, ela produz seu espaço, o qual é também produtor desta mesma sociedade (LEFEBVRE, 2000). Neste sentido, cada momento histórico experimentado pela sociedade, em relação, produz um espaço com determinadas características aparentes e essenciais, isto é, ligadas à forma e ao conteúdo do espaço. Isto porque o espaço se produz por meio de diversas relações sociais, as quais são hierárquicas, desiguais e conflituosas.

Ao longo da História, o espaço foi produzido por meio de variados processos, tais como a formação de cidades com comércio pujante, concentrando pessoas e promovendo trocas culturais e o sistema de feudos que carregava em si um conteúdo de relações servis e de exploração.

A predominância do capital industrial nos séculos XIX e XX gerou a produção de um espaço que

\footnotetext{
1 Segundo este autor (2005, p.35): “O capital portador de juros (também designado "capital financeiro" ou simplesmente "finança” não foi levado ao lugar que hoje ocupa por um movimento próprio. Antes que se desempenhasse um papel econômico e social do de primeiro plano, foi necessário que os Estados mais poderosos decidissem liberar o movimento dos capitais e desregulamentar e desbloquear seus sistemas financeiros".

${ }^{2}$ A palavra "sociedade" é aqui empregada lato sensu, mas, se liga a ideia moderna de sociedade.
} 
expressava as relações de uma sociedade urbano-industrial. Em começos do século XXI, sob a dominância do sistema financeiro que dita a lógica da circulação e realização de capital, observa-se a reestruturação das áreas centrais da cidade, e no caso, da cidade do Rio de Janeiro, com o intuito de valorizar o solo da região por meio de incentivo à especulação imobiliária, facilitar a circulação de mercadorias, posicionar-se competitivamente no mercado global de cidades e, por fim, materializar no espaço da Operação Urbana Consorciada da Região do Porto do Rio de Janeiro (OUCRPRJ) conceitos como o de modernidade, de cidade global, turística, etc. Além disto, a facilitação da circulação de capital financeiro por meio das desregulamentações e liberalizações do setor financeiro (CHESNAIS, 1996) tornou extremamente fluida a passagem de capital de um setor da economia para o outro, o que é expresso pela emissão de títulos mobiliários para viabilizar a realização da operação urbana, pois podem permanecer na esfera financeira enquanto título ou serem vinculados ao solo por meio da construção de determinado empreendimento. Sendo assim, observa-se a articulação entre capital financeiro e capital imobiliário na produção do espaço da OUCRPRJ.

Nesta perspectiva, em 2009 foi assinada a Lei 101 de 23 de novembro, que rege a OUCRPRJ e delimita um perímetro de aproximadamente 5 milhões de $\mathrm{m}^{2}$ localizado nas áreas central e portuária da cidade do Rio de Janeiro. 0 texto desta operação urbana define a realização de obras infraestruturais na região, as quais são custeadas com verba proveniente da comercialização de Certificados de Potencial Adicional de Construção (CEPACs). Em 2011, os CEPACs foram ofertados publicamente pelo Município do Rio de Janeiro, e comprados em lote único pela Caixa Econômica Federal (CEF) por 3,5 bilhões de reais. A partir desta compra, a CEF criou o Fundo de Investimento Imobiliário da Região do Porto (FIIRP) o qual ficou responsável pela negociação dos CEPACs tanto no mercado secundário (BOVESPA) como com investidores imobiliários.

Ocorre que, atualmente, ainda há disponível para compra 91,20\% de CEPACs, os quais estão desvinculados do solo e não experimentam nenhuma valorização na esfera financeira na medida em que este ativo se revelou arriscado e insolvente.

Sendo assim, este artigo tem o objetivo de analisar a dinâmica da inversão de capital financeiro na produção do espaço da Operação Urbana Consorciada da Região do Porto do Rio de Janeiro por meio da exposição de seu mecanismo de financiamento realizado por meio da comercialização de CEPACs.

\section{Desenvolvimento}

A operação urbana que se dá nas regiões central e portuária da cidade do Rio de Janeiro se espelha nas operações urbanas ocorridas no município de São Paulo, tal como a Operação Urbana Consorciada Faria Lima ${ }^{3}$ sancionada em 2004 e financiada através da comercialização de CEPACs.

A Lei 101 de 23 de novembro de 2009 que rege a OUCRPRJ delimita seu perímetro por meio do desenho de diferentes recortes espaciais que revelam distintas valorizações futuras. Esta desigualdade na projeção das valorizações de cada recorte espacial contido no perímetro é resultado da estratégia do poder público municipal em fomentar o investimento imobiliário em determinados espaços do perímetro. Este foi dividido em setores, subsetores e faixas de equivalência (ver figura 1), que apresentam diferentes características com relação à sua condição de venda ${ }^{4}$.

\footnotetext{
${ }^{3}$ A mencionada operação urbana já foi regida por mais de uma Lei porque ocorreram modificações em seu texto. Toma-se aqui a última Lei que a rege: nº13.769 de 2004. Em 2015, havia apenas 36,24 \% de CEPACs disponíveis no mercado referentes à OUCFL.

${ }^{4}$ Segundo a Prefeitura, "cada subsetor tem um índice de aproveitamento máximo do terreno, que limita seu potencial construtivo de forma a evitar o adensamento desordenado. As faixas de equivalência se referem ao potencial de valorização econômica de cada sub-região, definindo a quantidade de Cepacs necessária para se desenvolver empreendimentos imobiliários. Como o potencial de valorização econômica varia de uma região para outra, a faixa de equivalência busca tratar de maneira diferenciada cada uma delas, de forma a não onerar sobremaneira os projetos tornando-os inviáveis. Assim, é pela faixa de equivalência que identificamos a proporção de Cepacs por $\mathrm{m}^{2}$ adicional consumido, de acordo com o tipo de empreendimento a ser desenvolvido, se residencial ou não". Retirado de: <http://portomaravilha.com.br/plesk-site-preview/portomaravilha.com.br/138.97.105.70/noticiasdetalhe/4194>.
} 


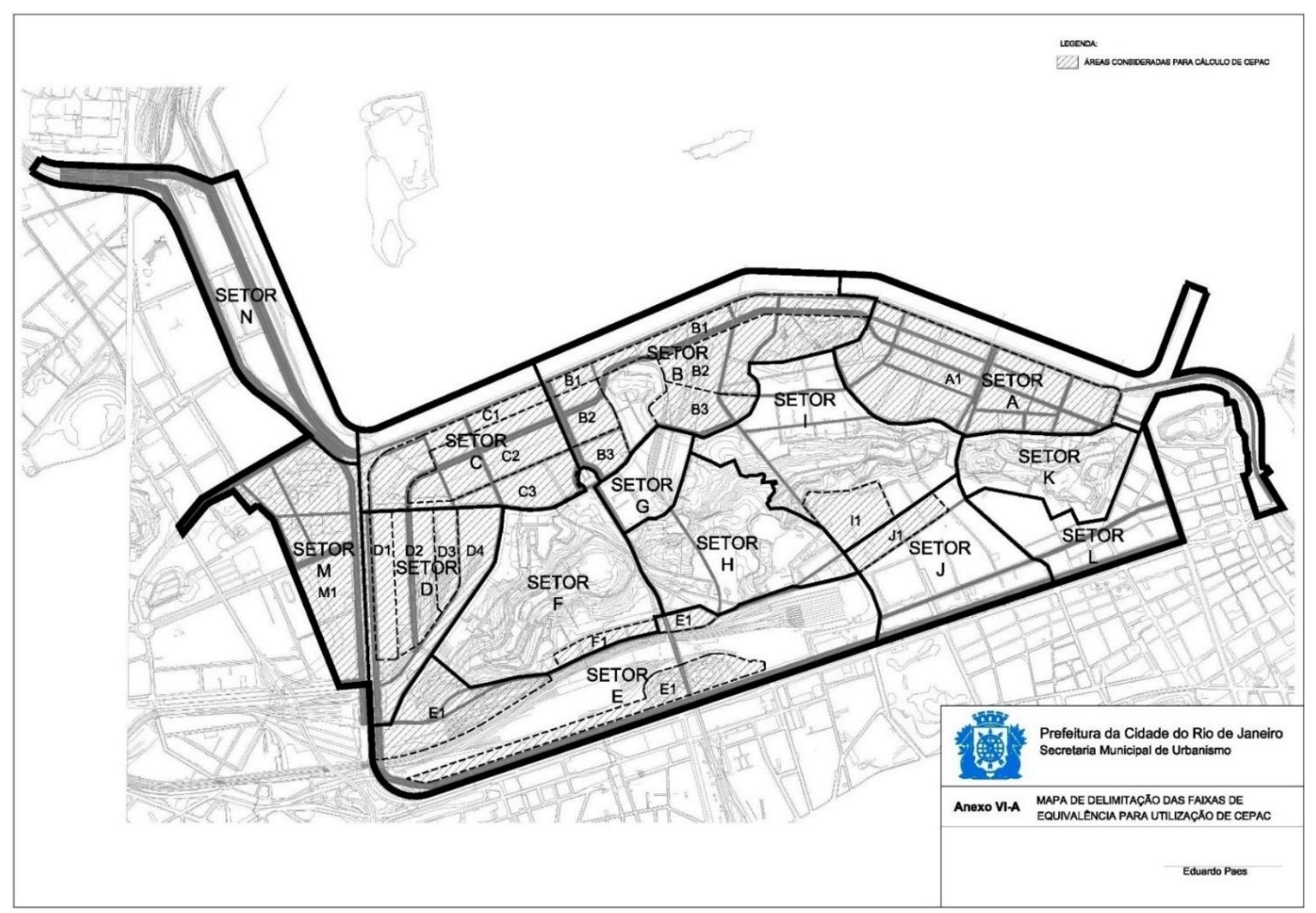

Figura 1: Mapa de delimitação das faixas de equivalência para utilização de Cepacs, s/escala Fonte: Lei Complementar 101/2009

As parcelas do espaço em destaque no mapa demonstram onde há comercialização de CEPAC e, portanto, articulação entre capital financeiro e imobiliário na produção espacial. Pode-se observar que as faixas de equivalência estão localizadas às margens da Baía de Guanabara (setores A,B e C) e no entorno da Avenida Francisco Bicalho (setores D e M). Os setores localizados no entorno dos Morros da Providência, Pedra Lisa e Conceição não apresentam comercialização de CEPACs (setores F, G, H, I, K), assim como a região da Avenida Presidente Vargas (setores E, J e L) e o setor N localizado na região do Caju. 0 fato de não haver oferta de CEPACs nos setores acima mencionados revela a estratégia do Estado em promover a valorização de um determinado setor em detrimento do outro. Considera-se que não há CEPACs disponíveis nos setores que cercam os três morros desta região porque seu espaço é consolidado e existe ali população residente que resiste ${ }^{5}$ à estratégia de especulação imobiliária dirigida pela Prefeitura.

A aposta na valorização do solo devido à presença de grandes empreendimentos imobiliários no perímetro da operação, se concretiza por meio de incentivos à compra de CEPACs em determinadas faixas de equivalência, as quais são tomadas como espaços de valorização em potencial. Este incentivo se faz por meio da quantidade de CEPACs necessária para se construir um empreendimento, que por sua vez se baseia na razão entre a metragem e número de CEPACs necessário, o qual varia de acordo com a faixa de equivalência onde o empreendimento se localizará. Abaixo, apresenta-se as referidas razões:

\footnotetext{
5 De fato, houve resistência dos moradores da região à realização das obras infraestruturais que compunham a operação urbana em questão. Criou-se o Fórum Comunitário do Porto, grupo de moradores que apontou por meio de reuniões de debate, realização de relatórios e redação de um blog, os acontecimentos que se davam nestas três comunidades afetadas pela operação.
} 


\begin{tabular}{|c|c|c|c|}
\hline Setor & $\begin{array}{c}\text { Faixa de } \\
\text { Equivalência }\end{array}$ & $\begin{array}{l}\text { Área Não } \\
\text { Residencial } \\
\text { Const. / CEPAC } \\
\text { (m2) }\end{array}$ & $\begin{array}{c}\begin{array}{c}\text { Área } \\
\text { Residencial }\end{array} \\
\text { Const. / CEPAC } \\
\text { (m2) }\end{array}$ \\
\hline $\mathrm{A}$ & $\mathrm{A} 1$ & 0,40 & 0,80 \\
\hline \multirow[b]{3}{*}{ B } & B1 & 0,50 & 0,80 \\
\hline & B2 & 0,70 & 1,00 \\
\hline & B3 & 0,80 & 1,20 \\
\hline \multirow[b]{3}{*}{ C } & C1 & 0,40 & 0,80 \\
\hline & C2 & 0,60 & 1,00 \\
\hline & C3 & 0,80 & 1,40 \\
\hline \multirow[b]{4}{*}{ D } & D1 & 0,50 & 0,80 \\
\hline & D2 & 0,60 & 1,00 \\
\hline & D3 & 0,70 & 1,20 \\
\hline & $\overline{D 4}$ & 1,00 & 1,40 \\
\hline $\bar{E}$ & E1 & 0,40 & 1,20 \\
\hline $\mathrm{F}$ & F1 & 1,00 & 1,40 \\
\hline 1 & 11 & 1,00 & 1,20 \\
\hline $\mathrm{J}$ & J1 & 0,90 & 1,00 \\
\hline$M$ & $\mathrm{M} 1$ & 0,40 & 1,00 \\
\hline
\end{tabular}

Tabela 1: Tabela de Conversão

Fonte:http://www.portomaravilha.com.br/conteudo/canal_investido r/EstudodeViabilidade-OUCPRJ.pdf

A tabela apresenta que nas faixas de equivalência $\mathrm{A} 1 \mathrm{e} \mathrm{C} 1$, por exemplo, devido à razão de 1 CEPAC para cada $0,40 \mathrm{~m}^{2}$ do empreendimento, tem-se que para construir em $10.000 \mathrm{~m} 2$ nas faixas A1 e C1 é necessário adquirir 25.000 CEPACs, enquanto na faixa de equivalência D4, que apresenta razão de $1,00 \mathrm{~m}^{2}$ para cada CEPAC, basta adquirir 10.000 CEPACs. Sendo assim, a valorização diferencial projetada neste perímetro, revela os espaços onde o poder público associado a investidores do setor imobiliário define, por Lei, os espaços a ter maior potência na acumulação de capital.

Deve-se tomar em consideração o fato do Rio de Janeiro ter sido uma das cidade-sede da Copa do Mundo de 2014 e sede contínua dos Jogos Olímpicos de 2016 e, portanto, os espaços às margens da Baía de Guanabara foram estrategicamente pensados para serem utilizados na construção de hotéis e/ou edifícios corporativos. Além disto, deve-se ressaltar que a reestruturação das regiões central e portuária por meio de operação urbana tinha como um dos objetivos aumentar o número de turistas que frequentam a região, onde foram construídos dois museus, (Museu do Amanhã e Museu de Arte do Rio) e teve a Praça Mauá completamente remodelada numa espécie de tentativa de colocar este espaço à disposição de outro tipo de população, principalmente turistas e moradores da cidade que a partir de um movimento de remodelação se sentem atraídos por este espaço sem mesmo conhecer as os conflitos sociais que aconteceram durante este processo.

A concretização de uma operação urbana tendo como um dos objetivos a atração de turistas é uma prática comum dentro do ideário neoliberal de pensar e governar as cidades contemporâneas. O exemplo da reestruturação espacial da cidade de Barcelona por conta das Olimpíadas de 1992 é emblemático, entretanto, deve-se observar que a consolidação de conceitos como "desenvolvimento urbano" e "solvência financeira"6 se fez por meio da difusão de cartilhas elaboradas pelo BIRD /

\footnotetext{
${ }^{6}$ Por solvência financeira se entende aqui a solidez financeira no tratamento das fontes de ingressos e dos gastos e, no caso de algumas cidades, uma capacidade creditícia tal que as permita o acesso aos mercados de capitais. As operações de desenvolvimento urbano do Banco e o correspondente diálogo sobre políticas fomentam a adoção de sistemas claros e coerentes de ingressos e gastos locais, com transferências intergovernamentais transparentes e previsíveis, e prudência no endividamento do município, assim como contabilidade financeira, gestão de ativos e práticas de contratação geralmente aceitas. Para uma boa gestão das finanças urbanas é importante adotar um critério comercial para muitos dos serviços e das funções administrativas das cidades, sem perder de vista os interesses sociais. Este critério comercial também é indispensável para a participação do setor privado ou para a privatização dos serviços urbanos. Nos países e cidades cujos sistemas creditícios municipais seguem sendo rudimentares, o Banco continuará apoiando os intermediários financeiros
} 
Banco Mundial que definem diversas diretrizes e normas referentes a reestruturações urbanas e adaptações políticas e fiscais, as quais devem ser seguidas a partir da tomada de empréstimo junto a esta instituição financeira.

A influência e a efetiva inversão de capital do BIRD/Banco Mundial na reestruturação urbana de cidades como o Rio de Janeiro, constituem práticas ligadas à lógica do tipo financeirizada, porque projeta significativas modificações nos espaços das cidades por meio de financiamento via Parceria Público Privada (PPP) e negociação em mercado secundário. A tendência global à emissão de títulos por corporações e por Estados-nação (títulos da dívida pública) desde as liberalizações e desregulamentações do setor financeiro (CHESNAIS, 1996), associada à urgência na reestruturação espacial do centro do Rio de Janeiro a fim de adaptá-lo à dinâmica atual da acumulação, viabiliza e estimula a inversão de capital financeiro na produção do espaço, momento em que este se torna capital imobiliário. Por sua vez, as construtoras/incorporadoras que investem capital imobiliário na construção de edifícios dentro do perímetro, emitem títulos mobiliários ligados a esses empreendimentos. Sendo assim, a passagem de capital de um setor da economia para outro se efetiva por meio da extrema flexibilidade alcançada pelo movimento do capital financeiro (CARLOS, 2011).

Além disto, ao observar em outra escala, a Lei que rege a OUCRPRJ foi decretada em 2009, ano em que a economia estadunidense vivia sua mais intensa crise econômica, cuja essência advém do excesso de especulação financeiro-imobiliária, e diante do cenário de fragilização do sistema financeiro global, a Caixa Econômica Federal investe R \$ 3,5 bilhão em CEPACs da operação urbana do Porto Maravilha. Esta estratégia foi, sobremaneira, arriscada, porque, financeira. Hoje, observar-se que há, ainda, 91,20\% de CEPACs disponíveis no mercado secundário. Deve-se questionar se a compra do lote de CEPACs não foi uma estratégia da CEF com o intuito de especular com esses títulos mobiliários.

\section{Considerações Finais}

Este artigo teve o objetivo de expor alguns elementos da dinâmica de financiamento da OUCRPRJ por meio da comercialização de CEPACs. Este tipo de financiamento se realiza na esfera financeira e, portanto, se configura como uma estratégia arriscada na condução de uma operação urbana que tem efeitos na forma e no conteúdo social do espaço em que acontece.

A Lei 101 que rege esta operação foi decretada em 2009 e em 2017 existe ainda 91,20\% de CEPACs disponíveis para compra. Isto quer dizer que quase toda a extensão do perímetro não tem projetos imobiliários a si vinculados e, portanto, tem-se um imenso espaço na região central da cidade que foi circunscrito em nome desta operação urbana. Ao mesmo tempo em que se dá a nãoconstrução de empreendimentos, especula-se na esfera financeira com os ativos CEPACs.

Neste sentido, deve-se pensar a articulação entre capital financeiro e imobiliário na produção deste espaço de forma dialética. 0 processo de acumulação de capital se dá de forma simultânea, contínua e contraditória e, portanto, deve-se atentar às relações estabelecidas pelo Estado e pelos variados atores econômicos, os quais estão presentes em todos os setores econômicos e se beneficiam da fluidez do capital financeiro para reproduzir seu capital por meio de processos especulativos.

Além disto, o Estado associado a determinados atores econômicos promovem a reestruturação de espaços a partir de interesses pessoais e não por iniciativa voltada à melhoria dos serviços públicos e infraestrutura urbana para a população.

Nesta perspectiva, algumas questões permanecem. Qual foi a estratégia pensada pela CEF ao adquirir todos os CEPACs em 2011? Será a Operação Urbana Consorciada da Região do Porto do Rio

especializados, como os fundos de desenvolvimento municipal. As operações creditícias devem encorajar cada vez mais a transição a sistemas creditícios municipais em acordo com as leis de mercado, nos quais os departamentos financeiros do Banco e da CFI - Corporação Financeira Internacional - podem se apoiar mediante seu trabalho sobre a infraestrutura básica de mercado. 
de Janeiro uma estratégia de financiamento mal-sucedida?

\section{Referências}

ALVAREZ, Isabel Pinto. A produção e reprodução da cidade como negócio e segregação. In: CARLOS, Ana Fani Alessandri; Volochko, Danilo; Alvarez, Isabel Pinto. (Org.). A cidade como negócio. São Paulo: Contexto, 2015b. P.65-79.

ALVES, Glória da Anunciação. Transformações e resistências nos centros urbanos. In: CARLOS, Ana Fani Alessandri. (Org.). Crise urbana. São Paulo: Contexto, 2015a. P.143-154.

BANCO INTERNACIONAL PARA RECONSTRUÇÃO E DESENVOLVIMENTO/BANCO MUNDIAL, Cities in transition: World Bank Urban and Local Government Strategy, Washington, 2000.

CARLOS, Ana Fani Alessandri. A condição espacial. São Paulo: Contexto, 2011.

CHESNAIS, François (org.). A finança mundializada: raízes sociais e políticas, configuração, consequências. São Paulo: Boitempo, 2005.

CHESNAIS, François. A mundialização do capital. São Paulo: Xamã, 1996 a.

CHESNAIS, François. A mundialização financeira: gênese, custo e apostas. Lisboa: Instituto Piaget, 1996b.

FIX, Mariana. São Paulo cidade global: fundamentos financeiros de uma miragem. São Paulo: Boitempo Editorial, 2007.

HARVEY, David. Diecisiete contradicciones y el fin del capitalismo. 1.ed. Quito: Editorial IAEN, 2014.

HARVEY, David. O enigma do capital e as crises do capitalismo. São Paulo: Boitempo Editorial, 2011.

HARVEY, David. Os limites do capital. São Paulo: Boitempo, 2013.

HARVEY, David. O neoliberalismo: História e implicações. São Paulo: Loyola, 2008.

LEFEBVRE, Henri. A produção do espaço. Trad. Grupo "As (Im)possibilidades do urbano na metrópole contemporânea do Núcleo de Geografia Urbana da UFMG. (do original: La production de l'espace. $4^{\underline{a}}$ éd. Paris: Éditions Anthropos, 2000).

MARX, Karl. O capital: crítica da economia política: Livro I: o processo de produção do capital. São Paulo: Boitempo, 2013.

MARX, Karl. $O$ capital: crítica da economia política, livro terceiro: o processo global de produção capitalista, volume VI. Rio de Janeiro: Civilização Brasileira, 2008.

MARX, Karl. $O$ capital: crítica da economia política, livro terceiro: o processo global de produção capitalista, volume V. Rio de Janeiro: Civilização Brasileira, 2008. 